\title{
The Scottish Mathematics Support Network
}

\author{
Shazia Ahmed \\ Student Learning Service \\ University of Glasgow \\ shazia.ahmed@glasgow.ac.uk
}

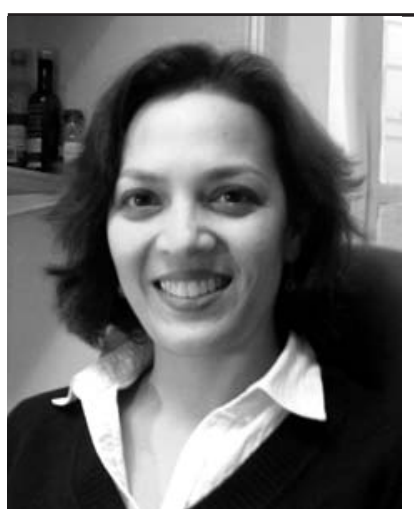

Kate Durkacz

School of Engineering and

Built Environment

Edinburgh Napier University

k.durkacz@napier.ac.uk

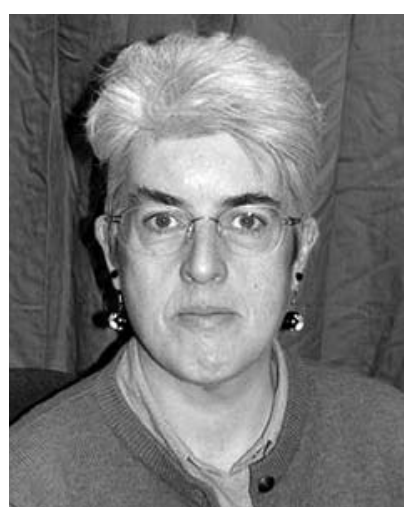

\section{Creation of Network}

The preliminary meeting of the Scottish Mathematics Support Network was held at the University of St Andrews on 18 July 2008. The aim of the meeting was to initialise a support network for people working in Scottish Universities and Colleges who were either currently providing or would like to be providing mathematical and statistical support to their students. A variety of institutions were represented: St Andrews University, which at this time had a dedicated Mathematics support tutor who worked with the Effective Learning Adviser (ELA); Dundee University and Robert Gordon University, which both had a similar arrangement; Abertay University which had both a Mathematics and a Statistics support tutor who were also part of the ELA team; Glasgow University which had just appointed a Mathematics support tutor, since their Mathematics support provision was due to start in September 2008; and Edinburgh Napier University, where the Mathematics support had been successfully run by the Mathematics lecturers for the last 20 years, with Statistics support being provided by Statistics lecturers. At the University of Aberdeen, the ELA team were aware of the growing need for a specialist Mathematics support tutor and were hoping that funding for such a post would be made available in the near future.

In recent years, there has been a serious decline in school leavers' mastery of basic mathematical skills, and there have been some fundamental changes in school Mathematics curricula. There has also been a big increase in the numbers attending universities, and non-traditional entry, such as from College, or Access programmes, or from the work place, has become more common. The consensus at the meeting was that students now need more assistance with their basic mathematical and statistical skills than they have required in the past, and that Mathematics support is an area which universities will need to focus on in future years.

This inaugural meeting was funded by sigma, the Centre of Excellence in Mathematics and Statistics Support, and included a presentation by Professor Tony Croft, the Director of the Mathematics Education Centre at Loughborough University. Professor Croft gave a history of the mathematics support at Loughborough University, detailed sigma activities and gave information about Mathcentre resources. A presentation about ScotELAs followed, where attendees were given an insight into the network for Effective Learning Advisers in Scottish Universities.

An informal discussion followed the two talks, which highlighted a lot of enthusiasm for supporting students with their mathematics skills. It was decided that a network would be formed and that meetings would be held annually at one of 
the participating institutions. In due course a dedicated website, hosted by St Andrews University, was set up (http://www.st-andrews.ac.uk/mathsnetwork/home/) and a mailing list of members, hosted by Glasgow University, was organised, enabling participants to readily stay in contact with each other and the network as a whole, throughout the year.

\section{Annual Meetings}

The second meeting of the network was held at Glasgow University in June 2009. This attracted a wider audience than the inaugural meeting, and included representation from the National University of Ireland (NUI), Maynooth. The Irish Mathematics Support Network was set up a couple of years prior to the Scottish network, and delegates from NUI were keen to share thoughts regarding the running of a network, and to discuss ideas with the Scottish participants. At this meeting, several of the delegates gave presentations, with topics including the provision and evaluation of mathematics support in various institutions and developments in mathematical e-learning. The highlight of the day was a hands-on Robotic Lego workshop, run by sigma-CETL staff.

The third meeting of the network was held at Edinburgh Napier University in June 2010, and attended by an enthusiastic audience which included predominantly previous attendees, but also staff from Strathclyde University, NUI Maynooth and a group of students from Edinburgh Napier University. This year, the presentations featured perspectives of Mathematics support from staff and students, and developments in resources for Mathematics support. With the network now firmly established, it was decided that the provision of a small committee would enable the network to run more effectively. The committee members included Shazia Ahmed (University of Glasgow), Sue Barnes (University of Strathclyde) and Kate Durkacz (Edinburgh Napier University)

The fourth meeting of the network was held at Strathclyde University in September 2011. Representatives from the usual institutions attended, along with a representative from Dundalk Institute of Technology (Ireland). This was a timely meeting as Dundalk were about to embark on setting up a new support service and were keen to get some ideas. This meeting also attracted interest and attendance from academic members of staff. Topics covered in the presentations and discussions included the use of technology in mathematics support and assessment, support for Statistics and issues surrounding funding for mathematics support. At this meeting, a change was made to the committee; Sue Barnes (Strathclyde University) retired and Katharine Preedy (University of St Andrews) joined the committee.

\section{Other Events}

At the June 2010 meeting, members of the network had discussed the possibility of holding a themed event in addition to the annual meeting. Given the level of interest, it was decided to hold a seminar day on the use of Electronic Voting Systems (EVS). This was held in November 2010 at the University of Glasgow. The delegates at this event were predominantly academic staff although there were several Mathematics support staff in attendance along with sigma representation. The speakers from Glasgow Caledonian University, Strathclyde University, Edinburgh Napier University and Glasgow University gave talks ranging from very practical uses of EVS in various subject areas to the more pedagogical aspects of using EVS. This was a very successful event and forged new and deeper links between the network and academics.

Two of the committee members had attended a Resource Development Workshop in June 2011 which had been organised by sigma at the University of Coventry. Inspired by this, the network is planning to hold a similar workshop at Glasgow in February 2012. Some members of the network have expressed an interest in using a new JISC-funded question authoring tool to create QTI compliant, randomised questions for mathematics formative e-assessment, whereas others are keen to develop other resources, possibly in collaboration with colleagues from other universities. Further details will be made available on the network website (http://www.st-andrews.ac.uk/mathsnetwork/home/) or by emailing the authors.

\section{Feedback from Members}

The Scottish Mathematics Support Network has now been running for more than three years, and has established itself as having an important role in supporting its members. Feedback regarding the annual meetings has been very positive, as the benefits of being able to network with others engaged in the role of Mathematics support have been appreciated. Having the opportunity to share new ideas, strategies and experiences both on providing Mathematics support and on overcoming problems has also been of importance. Feedback e-mails received following the annual meetings have been very positive, describing these sessions as "super events with very dynamic and enthusiastic presenters, comprising interesting talks and conversations and with sizeable audiences". A common comment is that the attendee has "come away with lots of ideas and things to ponder".

A general feeling amongst network members is that they appreciate having the opportunity to network with other practitioners in the field of Mathematics and Statistics support, and that the meetings allow the discussion of problems and solutions. One of the newer members of the network, who has only recently moved into a Mathematics support role, reported that the advice from colleagues in the network has been invaluable in the process of settling into their new post. In the present difficult financial climate many institutions have limited funds for Mathematics support, so the ability to share experience and materials effectively 
across the network is of increasing importance. A single person in an institution in this role can often feel that they are working in a vacuum, but find that the network "also helps to prevent the isolation inevitable where there is only one person performing what can be an under valued role". A member, mainly engaged with the service teaching of mathematics, finds the meetings "good for morale", as there is a level of enthusiasm for such work which is not readily available at their home institution. Other views on the network include "useful forum for peer discussion of practice", and "I think it will also help me to be able to say something to my management about how other Scottish universities are progressing maths and stats support services".

\section{Looking Ahead}

Many of the network members are the sole providers of Mathematics and Statistics support at their home institution, and can feel quite vulnerable to potential economies. Many institutions only have part-time or temporary contract or non-academic contract staff in these support roles, which suggests that they are not seen as important. However, such roles are vital for the success of the students on technical degrees. Several network members have commented that they feel that there is safety in numbers, and it is now easy to make their institution aware that such support is available at a wide range of Scottish Universities and Colleges. The network provides a much needed service for such members; they may not have others in their workplace to discuss issues with, but they have a whole network of like-minded people to bounce ideas off.

As well as building strong links amongst the providers of Mathematics support, the network has also started to attract interest from academic staff involved in teaching mathematical and technical modules. This is an area which is important to expand, as Mathematics and Statistics support could be even more effective with input from the academic staff whose students need assistance. A closer working relationship with academic staff would enhance their awareness of the techniques and topics that the students are having difficulties with, and enable lectures and tutorials to be better targeted.

It should be noted that all the annual meetings of the network so far have been funded by sigma, the Centre of Excellence in Mathematics and Statistics Support, which has also funded the website and the EVS seminar. Thanks to this generous and continuing support, for which our members are most grateful, the Scottish Mathematics Support Network has been developed and is flourishing. We hope that the network will continue to be an accessible and useful point of contact for those wishing to find out more about Mathematics support in Scotland.

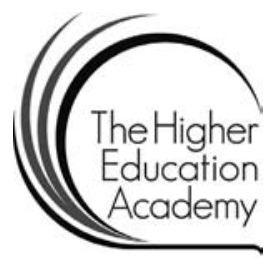

\section{HEA STEM Maths, Stats and OR Workshops} for Postgraduate Students who Teach

The HEA will be running a series of one-day workshops to support postgraduate students who teach in Mathematics, Statistics and Operational Research (MSOR). The workshops are discipline specific and will be delivered by MSOR subject specialists. There will be no charge for postgraduate students from HEA subscribing institutions attending the workshops. Information about workshops in Scotland will be provided soon. Workshops will be running in the autumn at the following universities.

- Queen's University of Belfast, 18 September 2012

- University of Southampton, 24 September 2012

- University of Leeds, 26 September 2012
- University of Nottingham, 27 September 2012

- Queen Mary, University of London, 28 September 2012

- University of Bristol, 8 October 2012

- University of Sheffield, 9 October 2012

- University of Manchester, 1 November 2012

- Lancaster University, 9 November 2012

- University of Leicester, 14 November 2012

For further details of the workshops and to book a place please go to

http://www.heacademy.ac.uk/disciplines/maths-stats-or-new-lecturers 